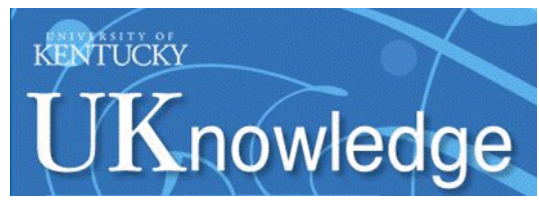

University of Kentucky

UKnowledge

Chemical and Materials Engineering Faculty

Publications

Chemical and Materials Engineering

3-27-2017

\title{
Chemically Stable Artificial SEI for Li-Ion Battery Electrodes
}

Qinglin Zhang

University of Kentucky, qinglinzhang@uky.edu

Lei Han

University of Kentucky

Jie Pan

University of Kentucky, jie.pan@uky.edu

Zhi Chen

University of Kentucky, zhi.chen@uky.edu

Yang-Tse Cheng

University of Kentucky, yang.t.cheng@uky.edu

Follow this and additional works at: https://uknowledge.uky.edu/cme_facpub

Part of the Chemical Engineering Commons, Materials Science and Engineering Commons, and the Physics Commons

Right click to open a feedback form in a new tab to let us know how this document benefits you.

\section{Repository Citation}

Zhang, Qinglin; Han, Lei; Pan, Jie; Chen, Zhi; and Cheng, Yang-Tse, "Chemically Stable Artificial SEI for LiIon Battery Electrodes" (2017). Chemical and Materials Engineering Faculty Publications. 39.

https://uknowledge.uky.edu/cme_facpub/39

This Article is brought to you for free and open access by the Chemical and Materials Engineering at UKnowledge. It has been accepted for inclusion in Chemical and Materials Engineering Faculty Publications by an authorized administrator of UKnowledge. For more information, please contact UKnowledge@lsv.uky.edu. 


\section{Chemically Stable Artificial SEI for Li-Ion Battery Electrodes}

\section{Digital Object Identifier (DOI)}

https://doi.org/10.1063/1.4979108

\section{Notes/Citation Information}

Published in Applied Physics Letters, v. 110, issue 13, 133901, p. 1-5.

This article may be downloaded for personal use only. Any other use requires prior permission of the author and AIP Publishing.

The following article appeared in Applied Physics Letters, v. 110, issue 13, 133901, p. 1-5 and may be found at https://doi.org/10.1063/1.4979108. 


\title{
Chemically stable artificial SEI for Li-ion battery electrodes
}

\author{
Qinglin Zhang, ${ }^{1, a), b)}$ Lei Han, ${ }^{2, a)}$ Jie Pan, ${ }^{1, a)}$ Zhi Chen, ${ }^{2}$ and Yang-Tse Cheng ${ }^{1}$ \\ ${ }^{1}$ Department of Chemical and Materials Engineering, University of Kentucky, Lexington, Kentucky 40506-0046, \\ USA \\ ${ }^{2}$ Department of Electrical and Computer Engineering, University of Kentucky, Lexington, Kentucky 40506-0046, \\ USA
}

(Received 8 November 2016; accepted 10 March 2017; published online 27 March 2017)

\begin{abstract}
The importance of coating's chemical stability in lithium-ion batteries has been demonstrated by this study. It is well known that the mechanical properties determine the cycle life, and chemical stability or chemical degradation rate determines the calendar life. In this study, we used $\mathrm{HfO}_{2}$ coatings prepared by atomic layer deposition as an example to show the chemical stability of the coatings for lithium ion battery electrodes. Published by AIP Publishing.

[http://dx.doi.org/10.1063/1.4979108]
\end{abstract}

Lithium ion batteries (LIBs) have been the choice of energy storage systems for portable electronic devices, uninterruptible power supplies, and electric vehicles. Exploring novel electrode materials with higher capacity, better rate capability, longer life, and lower cost is in urgent need for using LIBs in wider applications. For example, Si electrodes are able to deliver over $3600 \mathrm{~mA} \mathrm{~h} / \mathrm{g}$ capacity, but the cycle life and calendar life are still too short due to both intrinsic issues of electrodes (such as large volume change) and surface chemical instability. ${ }^{1-6}$

Mechanical and chemical degradation are the two major degradation mechanisms of most LIBs. Usually, the cycle life is determined by the mechanical degradation rate and the calendar life is determined by the rate of chemical degradation. The stability of the electrode-electrolyte interphase, or solidelectrolyte interphase (SEI), in a non-aqueous electrolyte is critically important for stabilizing the electrodes and enabling the long-term cyclability. ${ }^{7-10}$ The stability of the SEI can significantly influence the life of LIBs. Intensive research efforts have been devoted to designing the SEI by incorporating electrolyte additives, such as FEC (Fluoroethylene Carbonate), VC (Vinylene Carbonate), and LiBOB (Lithium Bis(oxalato) borate). ${ }^{11-14}$ These electrolyte additives can help form stable SEIs on electrodes to prevent further decomposition of electrolytes. Even with the additives, however, the formation of the SEI is still a Li consuming process, which causes irreversible Li loss (or capacity loss) during the formation cycles.

In addition to electrolyte additives, surface coatings or artificial SEIs (a-SEIs) have been employed to improve the functionalities of electrodes. ${ }^{15,16}$ There are many advantages of a-SEIs, such as reducing the irreversible capacity loss, improving the kinetics of electrodes, and better compositional control of SEI layers. ${ }^{17,18}$ The a-SEIs should be electronically insulating (suppress the electrolyte reduction), $\mathrm{Li}$ ion conducting, and chemically stable. ${ }^{7}$

Recently, several coatings made by atomic layer deposition (ALD) have been demonstrated to be effective a-SEIs to protect the electrodes. There are many advantages of ALD, such as the film was deposited under a relative low temperature with

\footnotetext{
${ }^{a)}$ Q. Zhang, L. Han, and J. Pan contributed equally to this work.

${ }^{b)}$ Author to whom correspondence should be addressed. Electronic mail: qinglinzhang@uky.edu.
}

controllable thickness of atomic precision, accurate stoichiometry, and excellent uniformity and conformity. ${ }^{16,19-22} \mathrm{TiO}_{2}$, $\mathrm{Al}_{2} \mathrm{O}_{3}, \mathrm{ZnO}_{2}, \mathrm{SnO}_{2}$, and $\mathrm{SiO}_{2}$ coatings are used as protection layers for both cathodes and anodes of LIBs. ${ }^{23,24}$

In this work, we introduce hafnium oxides $\left(\mathrm{HfO}_{2}\right)$ as aSEIs to stabilize $\mathrm{Si}$ electrodes. $\mathrm{HfO}_{2}$ has been widely used as high-k dielectrics in the semiconductor industry. Moreover, $\mathrm{HfO}_{2}$ is known for its stability under various conditions, ${ }^{25,26}$ which may be desirable for LIB applications. We use X-ray photoelectron spectroscopy (XPS) to demonstrate the stability of $\mathrm{HfO}_{2}$ coatings by comparing the cycle-aged electrode coatings with freshly prepared coated electrodes. The results show that, unlike other coatings that change their chemical compositions after cycling, $\mathrm{HfO}_{2}$ coatings maintain chemically stability, hence improving the cycling stability of the $\mathrm{Si}$ electrode significantly.

Silicon thin film electrodes were deposited on a copper current collector by radio frequency (RF) magnetron sputtering. The sputtering rate was $0.1 \mathrm{~nm} / \mathrm{s}$, and the thickness was controlled to be $100 \mathrm{~nm}$.

ALD has been used to grow metal oxide thin films with uniform chemical composition and precisely controlled thickness because of ALD's self-limiting growth mechanism. Thin films with consistent quality can be grown by ALD conformally on a variety of substrates, including substrates with high aspect-ratios, rough and porous, which tremendously broadens the application field of ALD. ${ }^{27,28}$ In this work, $\mathrm{HfO}_{2}$ was deposited on $\mathrm{Si}$ electrodes and wafers using ALD (Cambridge NanoTech, Inc.) at $300^{\circ} \mathrm{C}$. The Hf atoms were provided by the amide precursor tetrakis(dimethylamido)hafnium (TDMAH), and the oxidant was $\mathrm{H}_{2} \mathrm{O}$. TDMAH and $\mathrm{H}_{2} \mathrm{O}$ were supplied sequentially into the ALD chamber with TDMAH supplied first. TDMAH was heated up to $75^{\circ} \mathrm{C}$ to provide a high enough vapor pressure. The nitrogen carrier gas was provided at a flow rate of $20 \mathrm{sccm}$ (standard cubic centimeters per minute). The pulse time of $20 \mathrm{~s}$ was long enough to meet the saturation requirement of each ALD cycle. After deposition of $\mathrm{HfO}_{2}$, a multi-angle Spectroscopic Ellipsometer (J. A. Woollam M3000 V) was used to measure the coating thickness and optical constants (refractive index, $\mathrm{n}$, and extinction coefficient, $\mathrm{k}$ ) of the thin $\mathrm{HfO}_{2}$ films. 


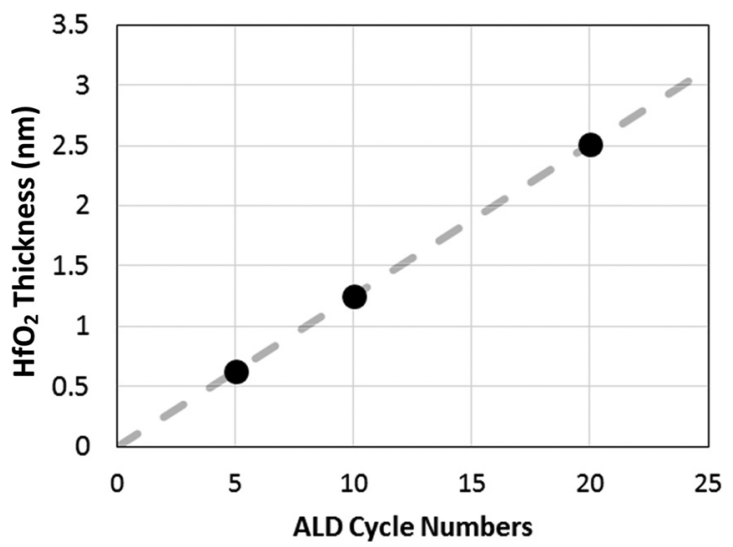

FIG. 1. Measured thickness vs. ALD cycle number of $\mathrm{HfO}_{2}$ ALD films.

$\mathrm{Si}$ and $\mathrm{HfO}_{2}$ coated $\mathrm{Si}$ electrodes were used as working electrodes. Lithium metal foil was used as counter and reference electrodes. CR 2025 coin cells (Hohsen) were assembled in an Ar filled glovebox (MBraun) with control of oxygen and moisture concentration below $0.1 \mathrm{ppm}$. A microporous membrane (Celgard 3501) was used as the separator. $1 \mathrm{M} \mathrm{LiPF}_{6}$ in ethylene carbonate and diethyl carbonate (EC:DEC 1:1 volume ratio, BASF) was used as the electrolyte. The Biologic VMP3 was used to cycle the coin cells between 1.2 and $0.05 \mathrm{~V}$ vs. $\mathrm{Li} / \mathrm{Li}^{+}$under a charge/discharge rate of $\mathrm{C} / 3$ ( $1 \mathrm{C}$ corresponds to $3600 \mathrm{~mA} / \mathrm{g}$ ). Electrochemical impedance spectroscopy (EIS) was conducted in twoelectrode coin cells at assigned voltages. The coin cells were rest for $24 \mathrm{~h}$ until stabilized before EIS measurements. The frequency range applied was $1 \mathrm{MHz}$ to $10 \mathrm{MHz}$. The fitting of equivalent circuit was performed using the EC-Lab software (Biologic).

A Thermo Scientific K-Alpha XPS system with a monochromatic $\mathrm{Al} \mathrm{K} \alpha$ source $(1486.6 \mathrm{eV})$ was used for chemical analysis of coatings and SEIs on the electrodes before and after electrochemical cycling. The post-cycled electrodes were harvested from the dissembled coin cells, washed with dimethyl carbonate (DMC) in the Ar-filled glovebox before transferring to the XPS analysis chamber. The transferring process was completed by a specially designed air-tight transfer holder to avoid sample exposure to air.

During the deposition, a Si wafer was placed adjacent to the $\mathrm{Si}$ electrodes in the ALD reaction chamber as a thickness reference. The as prepared $\mathrm{HfO}_{2}$ film on the $\mathrm{Si}$ wafer was characterized by ellipsometry to confirm the thickness. The measured thickness for 5 layers, 10 layers, and 20 layers of $\mathrm{HfO}_{2}$ is $0.63 \mathrm{~nm}, 1.25 \mathrm{~nm}$, and $2.51 \mathrm{~nm}$, respectively. The measurement error is within $3 \%$ of the measured thickness. Fig. 1 is the plot of $\mathrm{HfO}_{2}$ thickness versus ALD layer numbers; the linear growth is an outstanding feature of ALD because $\mathrm{HfO}_{2}$ was deposited atomic layer by atomic layer. The deposition rate $(1.25 \AA$ /layer $)$ was calculated by the slope of the growth line, and it matches well with previous studies of $\mathrm{HfO}_{2}$ growth. ${ }^{26,27,29,30}$

Fig. 2 shows the cycling performance of bare Si electrodes, Si coated with 5 layers $(0.63 \mathrm{~nm}), 10$ layers $(12.5 \mathrm{~nm})$, and 20 layers $(25.1 \mathrm{~nm})$ of $\mathrm{HfO}_{2}$ under the constant current with a charge/discharge rate equivalent to $\mathrm{C} / 3(\mathrm{C}=3600 \mathrm{~mA} / \mathrm{g})$. Fig. 2 (left) shows capacity retention. The first cycle discharge capacity is about $3600 \mathrm{mAh} / \mathrm{g}$ and then stabilized around $2800 \mathrm{mAh} / \mathrm{g}$ for all samples. After 100 cycles, the Si electrode coated with 20 layers of $\mathrm{HfO}_{2}$ shows $2019.58 \mathrm{~mA} \mathrm{~h} / \mathrm{g}$ capacity, with $70.1 \%$ capacity retention. In comparison, the bare $\mathrm{Si}$ electrode without coating only shows a capacity of $1331.73 \mathrm{mAh} / \mathrm{g}$ after 100 cycles, with $45.9 \%$ capacity retention. The $\mathrm{Si}$ electrodes coated with 5 and 10 layers of $\mathrm{HfO}_{2}$ show improved performance, but not as good as that of 20 layers. The Coulombic efficiency (CE) is an important indicator to evaluate the performance of LIB electrodes. Fig. 2 (Right) shows the CE of different samples. The first cycle CE was $68.3 \%, 79.7 \%, 78.6 \%$, and $78.5 \%$ for the bare Si electrode, with 5, 10, and 20 layers of $\mathrm{HfO}_{2}$ coatings, respectively. The low first cycle $\mathrm{CE}$ can be attributed to the formation of the SEI on the electrodes and stainless steel conducting coin-cell cases. The results show that, with the $\mathrm{HfO}_{2}$ coatings, the first cycle CE has been improved, due to the suppressed formation of the SEI on the electrodes. The CE for coated samples raised above 99\% during the first 20 cycles, in comparison with bare $\mathrm{Si}$ samples, which is lower than $99 \%$. The majority of the reactions during SEI formation is caused by electrolyte reduction. The improved $\mathrm{CE}$ for coated samples indicates that, compared with naturally formed SEIs, $\mathrm{HfO}_{2}$ coatings can be a more effective in blocking the electrons from contributing to electrolyte reduction reactions.

To characterize the kinetic properties of the coated Si electrodes, EIS was carried out before and after cycling. Fig. 3 shows the Nyquist plots of AC impedance spectra recorded for bare $\mathrm{Si}$ electrodes and $\mathrm{Si}$ coated with $\mathrm{HfO}_{2}$
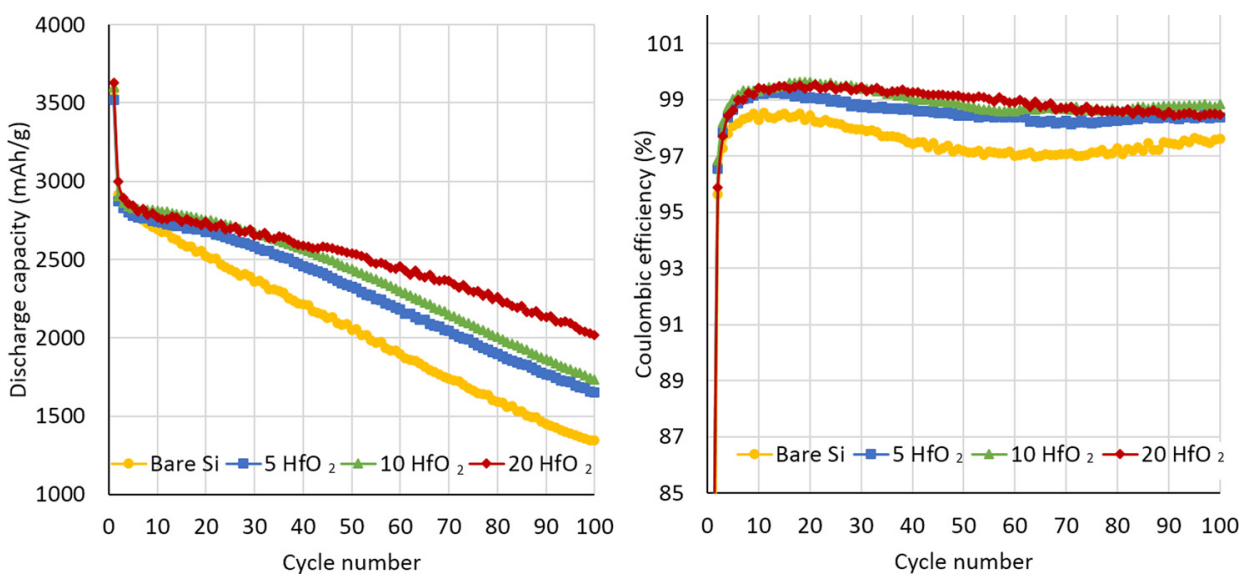

FIG. 2. (Left) Discharge (lithiation) capacity (Right) Coulombic efficiency of bare Si thin film electrodes, Si with $5 / 10 / 20$ layers of $\mathrm{HfO}_{2}$ coatings. 

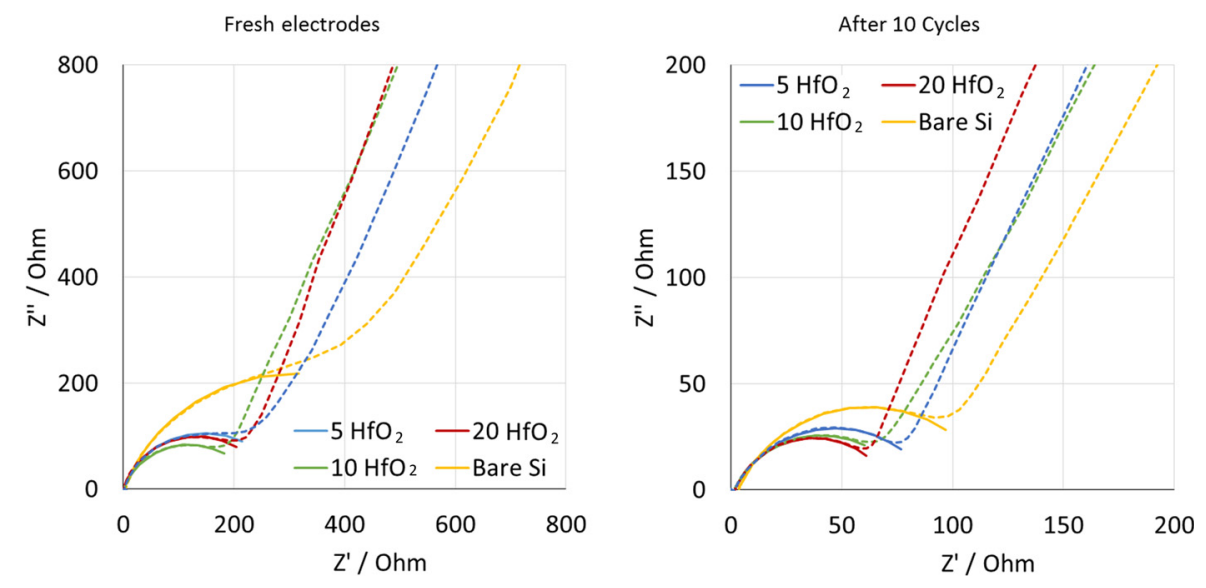

FIG. 3. Comparison of the EIS spectra for fresh and cycle-aged (10 cycles) electrodes. The EIS spectra for cycle aged $\left(10\right.$ cycles) with/without $\mathrm{HfO}_{2}$ coatings are shown. EIS was measured under open circuit voltage.
TABLE I. Interfacial resistance $\left(\mathrm{R}_{\mathrm{int}}\right)$ of electrodes with/without $\mathrm{HfO}_{2}$ coatings, fit from the semicircle of EIS measurements.

\begin{tabular}{lcc}
\hline \hline & Fresh electrode $(\Omega)$ & After 10 cycles $(\Omega)$ \\
\hline Bare Si & 611.4 & 116.9 \\
$5 \mathrm{HfO}_{2}$ & 283.6 & 91.0 \\
$10 \mathrm{HfO}_{2}$ & 231.3 & 79.2 \\
$20 \mathrm{HfO}_{2}$ & 274.7 & 71.4 \\
\hline \hline
\end{tabular}

coatings at open circuit potential before and after cycling. The semi-circle (in the high frequency region) originates from the interfacial resistance $\left(\mathrm{R}_{\mathrm{int}}\right)$. The low frequency tail of EIS spectra corresponds to the semi-infinite diffusion or Warburg resistance. ${ }^{31}$ By fitting the semi-circles, we obtained the interfacial resistance which is given in Table I. For the fresh electrodes before cycling, the $\mathrm{HfO}_{2}$ coatings can significantly reduce the $\mathrm{R}_{\text {int }}$ from $600 \Omega$ (bare) to $200-300 \Omega$ (coated). We also compared the $\mathrm{R}_{\mathrm{int}}$ after 10 cycles, when the surface passivation has been stabilized. After 10 cycles, Si electrodes coated with 20 layers of $\mathrm{HfO}_{2}$ have the lowest $\mathrm{R}_{\text {int }}(71 \Omega)$, and compared with bare $\mathrm{Si}$ w/o coating, all $\mathrm{HfO}_{2}$ coated samples show reduced $\mathrm{R}_{\text {int }}\left(100 \Omega\right.$ for 5 layers of $\mathrm{HfO}_{2}, 79 \Omega$ for 10 layers of $\mathrm{HfO}_{2}$, and $117 \Omega$ for bare $\mathrm{Si}$ electrodes). The increased resistance results in incomplete charge/discharge of the cells, especially with increasing the cycling rate. ${ }^{32}$ The reduced $\mathrm{R}_{\text {int }}$ for 20 layers of $\mathrm{HfO}_{2}$ coated on $\mathrm{Si}$ electrodes indicates that the $\mathrm{HfO}_{2}$ coating reduces the $\mathrm{R}_{\text {int }}$ to more favorable values.

Fig. 4 compares the cyclic voltammetry (CV) curves of the bare $\mathrm{Si}$ electrode and 20 layers of the $\mathrm{HfO}_{2}$ coated $\mathrm{Si}$ electrode for the 1 st and 2 nd electrochemical cycles. There are three reduction peaks for the bare $\mathrm{Si}$ electrode in the 1st cycle: the peak around $0.5 \mathrm{~V}$ corresponding to the formation of the $\mathrm{SEI}^{16}$ and two peaks around $0.2 \mathrm{~V}$ and $0.1 \mathrm{~V}$ corresponding to $\mathrm{Li}$ insertion into $\mathrm{Si}$ electrodes. ${ }^{3,4}$ There are also two oxidation peaks during the reverse scan, corresponding to the Li extraction peaks, which match with the insertion peaks during the reduction scan. However, due to the irreversibility of SEI formation, there is no oxidation peak accounted for SEI formation. For the 2nd cycle, the formation of the SEI is largely complete; therefore, there are only two peaks each for $\mathrm{Li}$ insertion/extraction. For the $\mathrm{Si}$ electrode coated with $\mathrm{HfO}_{2}$, the SEI formation has been suppressed as seen from the absence of the SEI formation peak around $0.6 \mathrm{~V}$. This result can be correlated with the first cycle CE, which has been discussed earlier in this paper. However, the first cycle reduction curve is not perfectly overlapping with the 2 nd cycle, which means that there is still addition SEI formed, but the reactions are likely different from those on the bare Si electrodes.

XPS was used to track the changes of $\mathrm{HfO}_{2}$ coatings before and after cycling. Ar sputtering was used for depth profiling. Figs. 5(a) and 5(c) show the $\mathrm{HfO}_{2}$ coated on the Si electrode before cycling; (a) shows that only $\mathrm{Hf}^{4+}$ was found on the top surface of the $\mathrm{HfO}_{2}$ coating; (c) shows that both $\mathrm{Hf}^{4+}$ and metallic $\mathrm{Hf}^{0}$ were found with longer sputtering time and approached to the $\mathrm{HfO}_{2}$ and $\mathrm{Si}$ interface. ${ }^{33}$ There are two possible reasons for the existence of $\mathrm{Hf}^{0} 4 \mathrm{f}$ peaks: (1) the ion sputtering preferentially removes oxygen; and (2) metallic $\mathrm{Hf}$ is segregated to the $\mathrm{Si} / \mathrm{HfO}_{2}$ interface. ${ }^{33}$ Figs. 5(b) and 5(d) show the Hf 4f XPS spectra of the cycleaged electrode. For both Figs. 5(b) and 5(d), we observed the similar peaks to those of fresh samples. Unlike other metal oxide ALD coatings, such as $\mathrm{Al}_{2} \mathrm{O}_{3}, \mathrm{TiO}_{2}$, and $\mathrm{SiO}_{2}$, $\mathrm{HfO}_{2}$ coatings show good stability on the $\mathrm{Si}$ electrode upon cycling. ${ }^{16}$ Since the formation of LiMOx $(\mathrm{M}=\mathrm{Al}, \mathrm{Ti}, \mathrm{Si}$, etc.) is also a $\mathrm{Li}$ consuming process, the stability of $\mathrm{HfO}_{2}$ can help prevent additional Li loss during electrochemical cycling.
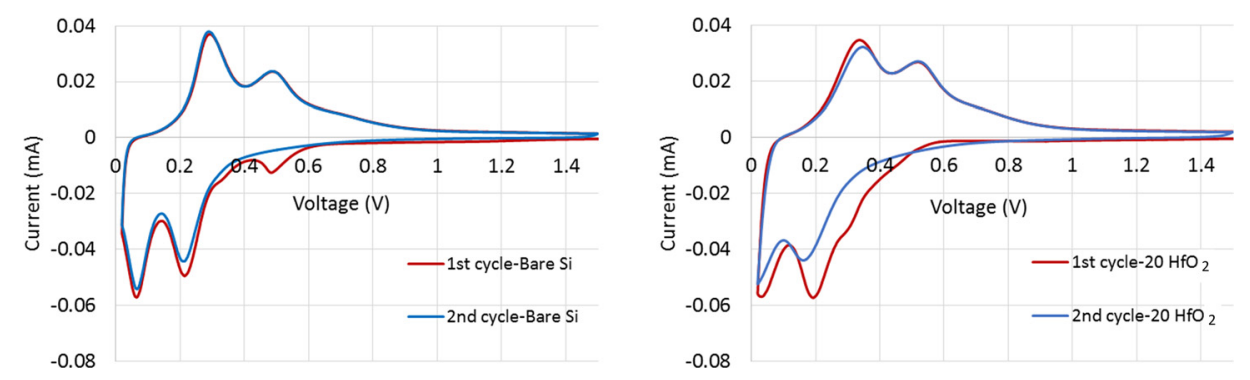

FIG. 4. Cyclic voltammetry curves of bare $\mathrm{Si}$ electrodes (left) and $\mathrm{Si}$ coated with 20 layers of $\mathrm{HfO}_{2}$ (right). 

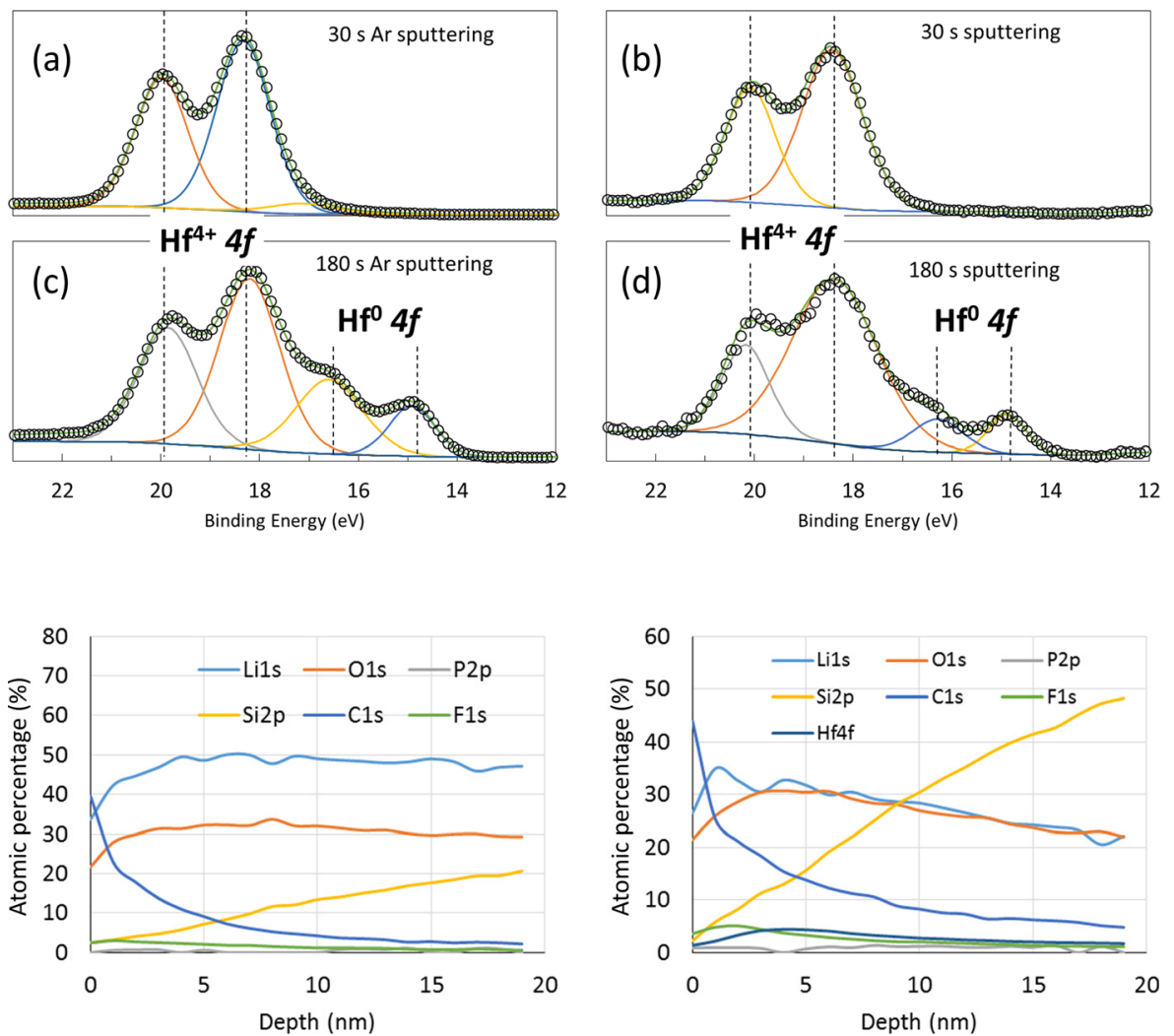

FIG. 5. The Hf-4f XPS spectra of the electrode surface before and after cycling; (a) and (c): before cycling; (b) and (d): after cycling (10 cycles).
Fig. 6 shows the depth profile of atomic percentage for the electrodes after cycling. Both electrodes show the existence of $\mathrm{Li}, \mathrm{O}, \mathrm{P}, \mathrm{C}, \mathrm{F}$, and $\mathrm{Si}$ elements, and the $\mathrm{HfO}_{2}$ coated sample shows, as expected, Hf signals. The $\mathrm{Hf}$ can be detected even after approximate $20 \mathrm{~nm}$ of sputtering, due to the surface roughness of Si thin-film electrodes. The low percentage of $\mathrm{P}-2 p$ means that most of the electrolyte molecules has been cleaned by DMC. The F signal is accounted for by the existence of $\mathrm{LiF}$ in the SEI. It is generally believed that $\mathrm{LiF}$ is favorable for improving the performance of the $\mathrm{Si}$ electrode. ${ }^{7,10,18,34,35}$ There is a higher $\mathrm{F}$ concentration for the $\mathrm{HfO}_{2}$ coated $\mathrm{Si}$ electrode, although the mechanism is still unclear. The percentage of $\mathrm{Si}$ is an indication of the thickness of the SEI: the more Si detected corresponding to less SEI founded at the detected depth level. In our experiment, the detection of $\mathrm{Si}$ on the $\mathrm{HfO}_{2}$ coated sample increased more rapidly with the increase in the sputtering time, which indicates that less or thinner SEI was formed on the $\mathrm{HfO}_{2}$ coated $\mathrm{Si}$ electrode. Our results indicate that $\mathrm{HfO}_{2}$ is chemically stable during the battery operation. This indication is consistent with the fact that the formation enthalpy should be very high for the formation of a stable $\mathrm{Li}_{x} \mathrm{HfO}_{\mathrm{y}}$ compound (either high temperature or high pressure is necessary to make this compound). ${ }^{36}$ In addition, it also shows that the $\mathrm{Li}$ ion is able to transport through the amorphous and nanometer thick thin film. But the kinetics of Li diffusion through amorphous $\mathrm{HfO}_{2}$ needs further theoretical exploration.

In conclusion, $\mathrm{HfO}_{2}$ coatings have been shown to be an effective surface passivation layer on the Si electrode to prevent the chemical degradation. As a highly insulating material, $\mathrm{HfO}_{2}$ can effectively block the electrons that play an important role in reducing the electrolyte. Compared with other oxide coatings, we found $\mathrm{HfO}_{2}$ to have a better stability under electrochemical cycling. In addition to previously recognized desirable properties of artificial SEIs, such as electronic insulating, ionic conducting, and mechanically "tough," we show in this work that the chemical stability is also desirable to achieve the long cycle life and shell life. We envision that this work will provide helpful guidelines to design better a-SEI for Li-ion cells.

The authors acknowledge the support by the Assistant Secretary for Energy Efficiency and Renewable Energy, Vehicle Technologies Office of the U.S. Department of Energy under Contract No. DE-AC02-05CH11231, Subcontract No. 7056410 under the Batteries for Battery Materials Research (BMR) Program. Partial Financial supports from National Science Foundation (Award No.: 1355438, Powering the Kentucky Bioeconomy for a Sustainable Future) and Department of Energy, Office of Energy Efficiency and Renewable Energy (EERE) (Award No.: DE-EE0007787) are also gratefully acknowledged.

${ }^{1}$ R. Chandrasekaran, A. Magasinski, G. Yushin, and T. F. Fuller, J. Electrochem. Soc. 157(10), A1139-A1151 (2010).

${ }^{2}$ J. Pan, Q. Zhang, J. Li, M. J. Beck, X. Xiao, and Y.-T. Cheng, Nano Energy 13, 192-199 (2015).

${ }^{3}$ M. W. Verbrugge, D. R. Baker, X. Xiao, Q. Zhang, and Y.-T. Cheng, J. Phys. Chem. C 119(10), 5341-5349 (2015).

${ }^{4}$ B. Lu, Y. Song, Q. Zhang, J. Pan, Y.-T. Cheng, and J. Zhang, Phys. Chem. Chem. Phys. 18(6), 4721-4727 (2016).

${ }^{5}$ T. Chen, Q. Zhang, J. Xu, J. Pan, and Y.-T. Cheng, RSC Adv. 6(35), 29308-29313 (2016).

${ }^{6}$ J. G. Xu, R. D. Deshpande, J. Pan, Y. T. Cheng, and V. S. Battaglia, J. Electrochem. Soc. 162(10), A2026-A2035 (2015).

${ }^{7}$ Q. Zhang, X. Xiao, W. Zhou, Y.-T. Cheng, and M. W. Verbrugge, Adv. Energy Mater. 5(5), 1401398 (2015).

${ }^{8}$ M. B. Pinson and M. Z. Bazant, J. Electrochem. Soc. 160(2), A243-A250 (2013). 
${ }^{9}$ G. M. Veith, M. Doucet, J. K. Baldwin, R. L. Sacci, T. M. Fears, Y. Wang, and J. F. Browning, J. Phys. Chem. C 119(35), 20339-20349 (2015).

${ }^{10}$ Q. Zhang, J. Pan, P. Lu, Z. Liu, M. W. Verbrugge, B. W. Sheldon, Y.-T. Cheng, Y. Qi, and X. Xiao, Nano Lett. 16(3), 2011-2016 (2016).

${ }^{11}$ K. Abe, K. Miyoshi, T. Hattori, Y. Ushigoe, and H. Yoshitake, J. Power Sources 184(2), 449-455 (2008).

${ }^{12}$ Y. An, P. Zuo, X. Cheng, L. Liao, and G. Yin, Electrochim. Acta 56(13), 4841-4848 (2011).

${ }^{13}$ V. Etacheri, O. Haik, Y. Goffer, G. A. Roberts, I. C. Stefan, R. Fasching, and D. Aurbach, Langmuir 28(1), 965-976 (2012).

${ }^{14}$ P. Ganesh, P. R. C. Kent, and D.-E. Jiang, J. Phys. Chem. C 116(46), 24476-24481 (2012).

${ }^{15}$ K. W. Schroder, A. G. Dylla, S. J. Harris, L. J. Webb, and K. J. Stevenson, ACS Appl. Mater. Interfaces 6(23), 21510-21524 (2014).

${ }^{16}$ X. Xiao, P. Lu, and D. Ahn, Adv. Mater. 23(34), 3911-3915 (2011).

${ }^{17}$ J. Li, X. Xiao, Y.-T. Cheng, and M. W. Verbrugge, J. Phys. Chem. Lett. 4(20), 3387-3391 (2013).

${ }^{18}$ J. Pan, Y.-T. Cheng, and Y. Qi, Phys. Rev. B 91(13), 134116 (2015).

${ }^{19}$ S. M. George, Chem. Rev. 110(1), 111-131 (2010).

${ }^{20}$ Q. Zhang, X. Xiao, Y.-T. Cheng, and M. W. Verbrugge, Appl. Phys. Lett. 105(6), 061901 (2014).

${ }^{21}$ L. Han and Z. Chen, ECS J. Solid State Sci. Technol. 2(11), N228-N236 (2013).

${ }^{22}$ L. Han and Z. D. Chen, ECS Trans. 58(10), 307-316 (2013).

${ }^{23}$ H.-Y. Wang and F.-M. Wang, J. Power Sources 233, 1-5 (2013).
${ }^{24}$ C. Li, H. P. Zhang, L. J. Fu, H. Liu, Y. P. Wu, E. Rahm, R. Holze, and H. Q. Wu, Electrochim. Acta 51(19), 3872-3883 (2006).

${ }^{25}$ B. H. Lee, L. Kang, R. Nieh, W.-J. Qi, and J. C. Lee, Appl. Phys. Lett. 76(14), 1926-1928 (2000).

${ }^{26}$ L. Han, J. Pan, Q. Zhang, S. Li, and Z. Chen, ECS J. Solid State Sci. Technol. 3(12), N155-N160 (2014).

${ }^{27}$ J. C. Hackley, J. D. Demaree, and T. Gougousi, J. Vac. Sci. Technol., A 26(5), 1235-1240 (2008).

${ }^{28}$ K. Li, S. Li, N. Li, D. A. Dixon, and T. M. Klein, J. Phys. Chem. C 114(33), 14061-14075 (2010).

${ }^{29}$ S. Li, L. Han, and Z. Chen, J. Electrochem. Soc. 157(11), G221-G224 (2010).

${ }^{30}$ L. Han and Z. D. Chen, ECS Trans. 61(2), 143-149 (2014).

${ }^{31} \mathrm{~S}$. Zhang, K. Xu, and T. Jow, Electrochim. Acta 51(8), 1636-1640 (2006).

${ }^{32}$ J. Christensen and J. Newman, J. Electrochem. Soc. 150(11), A1416-A1420 (2003).

${ }^{33}$ E. Filatova, A. Sokolov, A. Ovchinnikov, S. Y. Tveryanovich, E. Savinov, D. Marchenko, V. Afanas'ev, and A. Shulakov, J. Electron Spectrosc. Relat. Phenom. 181(2), 206-210 (2010).

${ }^{34}$ D. Aurbach, J. Power Sources 89(2), 206-218 (2000).

${ }^{35}$ J. Pan, Q. Zhang, X. Xiao, Y. T. Cheng, and Y. Qi, ACS Appl. Mater. Interfaces 8(8), 5687-5693 (2016).

${ }^{36}$ E. Bourret-Courchesne, S. E. Derenzo, and S. E. Taylor, U.S. patent 0148375 A1 (June 11, 2009). 


\section{Chemically stable artificial SEI for Li-ion battery electrodes}

Qinglin Zhang, Lei Han, Jie Pan, Zhi Chen, and Yang-Tse Cheng

Citation: Appl. Phys. Lett. 110, 133901 (2017); doi: 10.1063/1.4979108

View online: https://doi.org/10.1063/1.4979108

View Table of Contents: http://aip.scitation.org/toc/apl/110/13

Published by the American Institute of Physics

\section{Articles you may be interested in}

Suppression of conductivity deterioration of copper thin films by coating with atomic-layer materials Applied Physics Letters 110, 131601 (2017); 10.1063/1.4979038

Nitrogen chemical state in $\mathrm{N}$-doped $\mathrm{Cu}_{2} \mathrm{O}$ thin films

Applied Physics Letters 110, 131902 (2017); 10.1063/1.4979140

Mitigating thermal runaway of lithium-ion battery through electrolyte displacement Applied Physics Letters 110, 063902 (2017); 10.1063/1.4975653

Heterogeneous current collector in lithium-ion battery for thermal-runaway mitigation Applied Physics Letters 110, 083902 (2017); 10.1063/1.4975799

Fatigue mechanism verified using photovoltaic properties of $\mathrm{Pb}\left(\mathrm{Zr}_{0} 0.52 \mathrm{Ti}_{0.48}\right) \mathrm{O}_{3}$ thin films Applied Physics Letters 110, 133903 (2017); 10.1063/1.4979525

Bioassay using blocking temperature: Interparticle interactions between biofunctionalized magnetic nanoparticles conjugated with biotargets

Applied Physics Letters 110, 133701 (2017); 10.1063/1.4979142 